This is the post print version of the article, which has been published in Patient Education and Counseling January 2020, 103(1), 234-239. Available online 16 August 2019.

https://doi.org/10.1016/j.pec.2019.08.015

\title{
Developing theory- and evidence-based counseling for a health promotion intervention: A discussion paper
}

\author{
Sanni Tiitinen ${ }^{1}$, Sakari llomäki ${ }^{1}$, Jaana Laitinen ${ }^{2}$, Eveliina Korkiakangas ${ }^{2}$, Heli Hannonen ${ }^{2}$, Johanna \\ Ruusuvuori ${ }^{1}$ \\ ${ }^{1}$ Tampere University, Tampere, Finland \\ ${ }^{2}$ Finnish Institute of Occupational Health, Oulu, Finland
}

\begin{abstract}
Although the use of theories and evidence is often stressed in the development of health promotion interventions, this does not guarantee the success of an intervention. Thus, we need to reflect on intervention development processes that use different types of theories and evidence. In this paper, we provide a reflective discussion on how we identified evidencebased behavior change techniques and counseling themes for a health promotion intervention. In addition, we discuss the challenges that we encountered and what we learned during the process: a) a lack of previous research and meta-analyses, b) inconsistencies in evidence, c) integrating evidence and theories that have different starting points, and d) collaborating with researchers who represent different evidence and theories. During the process, we benefitted from having the clear goal of conducting evidence- and theory-based work. We solved the challenges by, for example, utilizing different types of evidence and being reflective about the reasons behind any inconsistencies in the evidence. In retrospect, we would have benefitted from closer collaboration between the teams that worked separately with different evidence. These kinds of reflective descriptions of development processes and the challenges encountered during them may help other researchers and professionals avoid encountering the same challenges.
\end{abstract}




\section{Introduction}

Theories and evidence play a key role in designing health promotion interventions. A theory is defined as a "set of interrelated concepts, definitions, and propositions that explain or predict events or situations by specifying relations among variables" [1]. By the term evidence, we refer to knowledge that can be reasoned with some scientific proof. When an intervention is designed, theories and evidence can help identify relevant determinants for health outcomes and select delivery methods for the intervention [2].

Although the utilization of theories and evidence is one factor that has been associated with the effectiveness of health promotion interventions [3-4], it does not automatically guarantee effectiveness [5]. Thus, we need reflective descriptions of the intervention development processes that use different types of theories and evidence in order to better understand what kind of utilization of these theories and evidence can be beneficial for developing effective interventions.

The recent development of categorization tools for theory utilization [6], the active components of interventions - behavior change techniques (BCT) [7] - and their mechanisms of action [8] have been important steps toward systematizing the utilization of theories and evidence to evaluate and report intervention methods in retrospect. In addition, tools such as Intervention Mapping [9] have been developed to highlight the theoretical assumptions in the design of interventions. However, each process of designing an intervention is unique, and researchers doing this need to reflect upon what applying evidence and theories mean in their specific case.

In this paper, we provide a reflective discussion on our process of developing active components and contents for a health promotion intervention. The intervention is conducted through a mobile application and aims to promote micro-entrepreneurs' work ability and recovery from work ${ }^{1}$ [12]. The theoretical framework of the intervention leans on the Self-determination Theory (SDT) [13] and the Behavior Change Wheel [14].

We focus here on the process of developing the intervention's counseling content, in which the themes of counseling were integrated with BCTs. By behavior change technique we refer to "an observable, replicable, and irreducible component of an intervention designed to alter or redirect causal processes that regulate behavior" as defined by Michie [7]. By counseling themes, we refer to topics and factors that are relevant for work ability and recovery from work. The process of intervention design also includes adapting the content to suit the software through which the content is delivered to the intervention participants, but the software design process is presented in a separate publication [15].

We focus on the following aspects of the process of developing the counseling content:

1. How we identified the evidence-based a) BCTs and b) counseling themes relevant for the intervention.

2. The challenges we encountered when identifying and integrating evidence-based BCTs and counseling themes with each other and with the intervention's theoretical framework, and what we learned from the challenges.

\footnotetext{
${ }^{1}$ Work ability can be defined as the balance between a person's resources and the demands of their work [10]. Recovery from work refers to activities that aim to replenish resources and to enable the continuation of work activities [11].
} 


\section{The processes of identifying evidence-based behavior change techniques and counseling themes}

We identified evidence-based BCTs and counseling themes using two teams: one from Tampere University, represented by Sanni Tiitinen, Sakari llomäki and Johanna Ruusuvuori; and the other from the Finnish Institute of Occupational Health $(\mathrm{FIOH})$, represented by Jaana Laitinen, Eveliina Korkiakangas and Heli Hannonen.

\subsection{Identifying evidence-based behavior change techniques}

To identify evidence-based BCTs, Tampere University's team conducted systematic literature searches of reviews and meta-analyses of health behavior change. We chose reviews and metaanalyses as sources of evidence because they are typically seen as providing a high-quality level of evidence [16] as compared with single studies, which always include multiple elements that can explain the effectiveness of the techniques.

Table 1. Selected BCTs and studies suggesting their effectiveness. Meta-analyses and metaregressions are marked with *. An intervention study marked with **.

\begin{tabular}{|c|c|c|}
\hline $\begin{array}{l}\text { Behavior change } \\
\text { technique }\end{array}$ & $\begin{array}{l}\text { Effectiveness identified in a study } \\
\text { focusing on face-to-face or all } \\
\text { types of interventions }\end{array}$ & $\begin{array}{l}\text { Effectiveness identified in a } \\
\text { study focusing on technology- } \\
\text { based interventions }\end{array}$ \\
\hline \multirow[t]{5}{*}{ Goals and planning } & Hankonen et al., 2015** [20] & Bort-Roig et al., 2014 [25] \\
\hline & McEwan et al., 2016* [21] & Nour et al., 2016* [26] \\
\hline & Michie et al., 2009* [22] & Schoeppe et al., 2016 [19] \\
\hline & Shilts et al., 2004 [23] & Webb et al., 2010* [4] \\
\hline & Williams \& French, 2011* [24] & \\
\hline \multirow[t]{4}{*}{ Self-monitoring } & Bird et al., 2013 [27] & Schoeppe et al., 2016 [19] \\
\hline & Gardner et al., 2016 [28] & \\
\hline & Michie et al., 2009* [22] & \\
\hline & Olander et al., 2013* [29] & \\
\hline \multirow[t]{4}{*}{ Feedback } & Michie et al., 2009* [22] & Bort-Roig et al., 2014 [25] \\
\hline & & Nour et al., 2016* [26] \\
\hline & & Schoeppe et al., 2016 [19] \\
\hline & & Webb et al., 2010* [4] \\
\hline \multirow[t]{3}{*}{ Social support } & Hankonen et al., 2015** [20] & Bort-Roig et al., 2014 [25] \\
\hline & Greaves et al., 2011 [30] & \\
\hline & Olander et al., 2013* [29] & \\
\hline \multirow{2}{*}{$\begin{array}{l}\text { Shaping knowledge \& } \\
\text { Natural consequences }\end{array}$} & McDermott et al., 2016* [31] & Nour et al., 2016* [26] \\
\hline & Williams \& French, 2011* [24] & \\
\hline Social comparison & Hartmann-Boyce et al., 2014* [32] & Webb et al., 2010* [4] \\
\hline Regulation & & Webb et al., 2010* [4] \\
\hline
\end{tabular}


In the preliminary phase, we concentrated on multi-behavioral, technology-based interventions that targeted the dietary habits, physical activity and sleep of working-age people with no particular diagnoses. We focused on these three target behaviors because, at the point of conducting the literature searches, these had been selected for inclusion in the intervention. We conducted searches in PubMed, Medline, Cochrane, CINAHL and PsycINFO, and after excluding duplicates, we had 705 references. As we found only three studies that focused on reviewing the effectiveness of the techniques and the features of interventions [17-19], we decided to extend our focus and conducted additional searches on meta-analyses and reviews that focused specifically on BCTs in both singleand multi-behavior, as well as both technology-based and face-to-face interventions. Finally, based on 15 previous studies, reviews and meta-analyses, we chose seven BCTs for a closer analysis of their potential in the intervention development. We prioritized evidence provided by meta-analyses and meta-regressions and supplemented it with evidence from systematic reviews. Table 1 presents the BCTs and studies according to the basis on which they were selected. To categorize the BCTs, we used Michie et al.'s [7] taxonomy.

\subsection{Identifying evidence-based counseling themes for the target group}

When identifying evidence-based counseling themes for the target group - micro-entrepreneurs we focused on behaviors that promote work ability and recovery from work, that is, the factors that had been chosen as the targeted long-term outcomes of the intervention [12].

$\mathrm{FIOH}^{\prime} \mathrm{s}$ team gathered previous research evidence on work ability and recovery from work in both small and large workplaces - and later systematized the literature into systematic and scoping reviews [11,33-36]. Based on previous research, we concluded that when enhancing work ability and recovery from work it is important to 1) promote work-related resources, such as social support, job control and breaks at work [37]; 2) decrease high demands and cognitive workload [37] and 3) promote personal resources through improving health-related habits and lifestyle areas such as physical activity, sleep and dietary habits [38-39]. Further, we observed that effective health promotion at work requires considering occupation-related factors, because 1 ) these factors set specific demands and conditions for health behavior [40] and 2) the effectiveness of interventions has shown to increase when the actions are tailored according to occupation and work tasks [36].

In order to tailor the counseling themes for the target group, we examined earlier surveys by the Federation of Finnish Enterprises, referred to as FIOH's team's experience in health promotion projects among micro-entrepreneurs [41], and referenced workshop discussions with both entrepreneurs themselves and representatives of the Federation of Finnish Enterprises. These sources of evidence highlighted that time management and stress management are relevant themes for micro-entrepreneurs. It also became evident that the social context of health promotion is different for micro-entrepreneurs than for workers at larger workplaces; micro-entrepreneurs may lack social contacts with co-workers. According to Finnish legislation, micro-entrepreneurs are not obliged to arrange occupational health services for themselves, nor to have organizations for safety or human resources.

As a result of combining the different types of evidence on relevant themes for the targeted longterm outcomes, counseling focused on the following themes: work ability, sleep, physical activity and sedentary behavior, recovery from work, stress management, time management and dietary habits. Each of the themes formed an independent thematic module in the mobile application.

\section{Challenges and learning from the process of identifying and integrating theories and evidence}

Next, we reflect on the challenges that we encountered during the process and what we learned from them in relation to identifying and integrating theories and evidence in the development of a health promotion intervention. 


\subsection{Utilizing different types of evidence due to a lack of previous research and meta-analyses}

The first challenge that we faced in relation to identifying evidence-based counseling themes and BCTs was a general lack of evidence. Although meta-analyses are traditionally considered to provide conclusive evidence [16], we were unable to gather all the relevant information from the metaanalyses. In relation to identifying evidence-based counseling themes, $\mathrm{FIOH}^{\prime} \mathrm{s}$ team found that previous scientific literature has neither broadly nor systematically addressed the work ability and recovery from work of micro-entrepreneurs [11]. Further, in relation to identifying evidence-based BCTs, earlier review articles have pointed out that the same BCTs are often used in both intervention and control groups [42], that no significant differences have been found between effective and ineffective techniques [43], and that intervention and control settings vary enormously [17]. All these features have contributed to the difficulty of conducting meta-analyses that provide systematic evidence of the effectiveness of BCTs.

We also noticed that it is difficult to find evidence of the effectiveness of BCTs because some of them have been utilized in interventions so infrequently. For example, the meta-analyses and reviews that we had gathered as the sources of identifying evidence-based BCTs did not highlight techniques related to restructuring one's physical and social environment, although we had hypothesized on the basis on the Behavior Change Wheel [14] that they could be relevant for ensuring opportunities for behavior change. However, it was crucial to study the meta-analyses carefully, and we found that Webb et al.'s [4] meta-analysis of 85 interventions included only two, and that Williams and French's [24] meta-analysis of 27 interventions included no interventions that used techniques related to restructuring antecedents or the environment.

Our solution to the lack of evidence provided by meta-analyses was to use multiple forms of evidence, such as different types of scientific literature, and experiences of using micro-entrepreneurs as a target group gained from earlier research and development projects. We also aimed to take into account the limits of different types of evidence. For example, we recognized that microentrepreneurs are a heterogeneous target group whose viewpoints the participants of previous projects do not comprehensively represent and thus, we aimed to utilize wide-ranging previous literature on the health promotion of all working-age adults. In retrospect, it would have been useful to gather the target group's experiences more systematically and comprehensively, as it turned out that we did not fully understand the prerequisites for successful interventions among microentrepreneurs.

\subsection{Highlighting theory-based operationalization of BCTs due to inconsistencies in evidence}

The second challenge that we encountered in relation to identifying evidence-based BCTs in particular was the inconsistencies in the existing evidence. For example, Michie et al. [22] reported that the effectiveness of self-monitoring is enhanced when it is combined with, for example, feedback in faceto-face interventions, and Webb et al. [4] identified feedback as an effective technique in technologybased interventions. On the other hand, McDermott et al. [31] demonstrated a negative association between target behavior and feedback on performance. Similar inconsistencies were observable in relation to the effectiveness of social support $[20,24,29-30]$. Thus, we had to reflect upon not only which BCTs were effective, but on the social mechanisms through which they could be effective, in which contexts and under which conditions [44-45].

Tampere University's team's expertise in social interaction was very useful when dealing with these kinds of inconsistencies in evidence. We leaned on the understanding that people co-construct the meanings of every utterance and activity in the minute practices of social interaction [46]. Thus, as we understood that the techniques of providing feedback and social support are fundamentally based on the logic of social interactions, we were able to see that the inconsistencies were understandable because the way in which the techniques are put into practice at the detailed level of (face-to-face and technology-based) interaction is crucial for how they are experienced. 
This understanding of the reasons behind the inconsistencies led us to treat the list of effective BCTs identified on the basis of previous meta-analyses and reviews as a mere starting point for a theorybased operationalization of the techniques. As we had decided to base the intervention on SDT [12], we used this in the operationalization of the selected BCTs. According to SDT, the building blocks for motivation are the needs for autonomy, competence and relatedness, and that to be motivated, one should feel that one is a voluntary source as well as a capable and appreciated agent of change [47]. Table 2 presents reflections on the selected BCTs from the perspective of SDT.

Table 2. Reflections from perspective of SDT on selected BCTs (in alphabetical order). An asterisk $\left({ }^{*}\right)$ indicates that previous meta-analyses or reviews identified the BCT as potentially beneficial (as described in Section 2).

\begin{tabular}{|c|c|}
\hline BCT & Reflections from perspective of SDT \\
\hline Feedback and monitoring & $\begin{array}{l}\text { To support competence, feedback should be informative and non- } \\
\text { judgmental; to support relatedness, it should be empathetic [48]. Rewards } \\
\text { were seen as unsuitable, as they would carry the risk of externalizing } \\
\text { motivation [13]. Competence can also be supported through feedback and } \\
\text { self-monitoring, which generate reflection and enable control of one's own } \\
\text { behavior [49]. }\end{array}$ \\
\hline Goals and planning* & $\begin{array}{l}\text { To support autonomy, users should be able to set their own goals; ones tha } \\
\text { are relevant to them; to support competence, the goals should be realistic } \\
\text { [48]. }\end{array}$ \\
\hline Identity & $\begin{array}{l}\text { Not identified as an effective/ineffective BCT in previous meta-analyses or } \\
\text { reviews because of scarce utilization in interventions. From the perspective } \\
\text { of SDT, identification of one's own values and integrating them into one's } \\
\text { own identity supports autonomy and internalized motivation [50]. }\end{array}$ \\
\hline Regulation* & Enhancing regulation can be seen as supporting competence. \\
\hline Self-belief & $\begin{array}{l}\text { Ambiguous and scarce evidence on effectiveness [see } 32,51,4] \text {. From the } \\
\text { perspective of SDT, self-belief should be supported in ways that support } \\
\text { competence and autonomy. }\end{array}$ \\
\hline $\begin{array}{l}\text { Shaping knowledge \& } \\
\text { Natural consequences* }\end{array}$ & $\begin{array}{l}\text { To support competence, users should feel they have sufficient knowledge } \\
\text { and skills to achieve their goals; to support autonomy, knowledge should be } \\
\text { relevant for the users [48]. }\end{array}$ \\
\hline Social comparison* & $\begin{array}{l}\text { The structure of a user's motivation affects the way in which they } \\
\text { experience social comparison [52]. As social comparison can be useful for } \\
\text { some users but not others, caution should be taken when implementing it. }\end{array}$ \\
\hline Social support* & $\begin{array}{l}\text { To support relatedness, social support should enhance the feeling of being } \\
\text { heard and appreciated; it must not undermine competence and social } \\
\text { support should avoid patronizing. }\end{array}$ \\
\hline
\end{tabular}

\subsection{The challenge of integrating evidence and theories with different starting points}

The third challenge we encountered, specifically at the point at which we started to integrate the $\mathrm{BCT}$ s and counseling themes into the counseling contents, was that the different types of evidence were based on different starting points that were incompatible. 
As previous literature or our theoretical framework did not provide straightforward insights into structuring the counseling contents, the structure and materials for each thematic module were drafted on the basis of a successful intervention of face-to-face and video-mediated counseling for micro-entrepreneurs and working-age people at a high risk of type 2 diabetes, arranged by FIOH [41]. The existing materials included information on and assignments to promote work ability.

In general, the utilization of the existing structure and materials significantly facilitated the drafting of the preliminary counseling contents. However, some unexpected inconsistencies ensued. Namely, the previous projects had been based on constructivist theory, and it became apparent that this was not fully compatible with the elements highlighted from the perspective of SDT. The functionality and apparent neutrality of the structure made it difficult to reflect upon the difficulties in relation to this inconsistency. As the structure and materials from the previous project had contributed to the very beginning of the integration process, it was practically impossible to modify them later without changing the counseling contents. Thus, we learned that to ensure compatibility, it is essential to reflectively plan the utilization of different types of evidence beforehand.

\subsection{The challenge of different researchers representing different evidence and theories}

The fourth challenge that we encountered was related to our working process, in which different researchers represented different evidence and theories.

As we have described, Tampere University's team was responsible for identifying evidence-based BCTs and the FIOH's team for identifying evidence-based counseling themes for the target group. Further, to integrate theory- and evidence-based BCTs and counseling themes, the teams collaborated in cyclical processes. FIOH's team drafted the preliminary structure and assignments for thematic modules. The drafts were then scrutinized by Tampere University's team, who identified the BCTs (utilizing Michie et al.'s [7] taxonomy) in these drafts, analyzed their overall occurrence, and compared them with the evidence on effective BCTs. In addition, Tampere University's team reflected upon the ways in which the BCTs were put into practice from the viewpoint of our theoretical framework, such as SDT. Based on this work, Tampere University's team suggested modifications such as including the BCT of goals and planning and partly replacing giving information with instructions on how to perform the target behavior.

At first, the teams worked separately. In the integration phase, we noticed that bringing the BCTs and counseling themes together was sometimes difficult, as these are not separate elements in the counseling content. This challenge was reflected in the difficulties of distributing the work and making decisions on the contents. In retrospect, it is clear that the two teams should have collaborated more from the beginning and proceeded by preparing one module at a time.

\section{Conclusions and practical implications}

Our aim in the development was to identify theory- and evidence-based BCTs and counseling themes and to integrate them into counseling contents for a health promotion intervention. Table 3 sums up the logic model of developing the counseling contents. Here, we have described one process of developing an intervention by looking at the challenges that may be encountered during the process and their possible solutions. 
Table 3. Logic model for counseling contents

\begin{tabular}{|c|c|c|c|c|c|}
\hline Resources & Activities & Short-term outcomes & \multicolumn{2}{|c|}{ Medium-term outcomes } & $\begin{array}{l}\text { Long-term } \\
\text { outcomes }\end{array}$ \\
\hline $\begin{array}{l}\text { Previous research on health } \\
\text { behavior change and health } \\
\text { promotion } \\
\text { Insight into target group } \\
\text { gained through previous } \\
\text { research and development } \\
\text { projects at FIOH } \\
\text { Insight into target group } \\
\text { gained through workshops }\end{array}$ & $\begin{array}{l}\text { Development of } \\
\text { counseling contents } \\
\text { for mobile } \\
\text { application: } \\
\text { Identifying } \\
\text { evidence- and } \\
\text { theory-based BCTs } \\
\text { Identifying } \\
\text { evidence-based } \\
\text { counseling themes } \\
\text { for target group }\end{array}$ & $\begin{array}{l}\text { Reflecting on one's own } \\
\text { current habits and life } \\
\text { situation } \\
\text { Setting relevant and } \\
\text { realistic goals through } \\
\text { reflection and/or behavior } \\
\text { change } \\
\text { Reading or listening to } \\
\text { materials that provide } \\
\text { relevant, new information } \\
\text { Completing assignments } \\
\text { that promote chosen goals }\end{array}$ & $\begin{array}{c}\text { Enhanced autonomy, } \\
\text { competence and } \\
\text { relatedness in relation } \\
\text { to behavior change to } \\
\text { promote work ability } \\
\text { and recovery from } \\
\text { work } \\
\qquad \\
\text { Motivation to reflect } \\
\text { upon one's work } \\
\text { practices and lifestyle } \\
\text { from the perspectives } \\
\text { of work ability and } \\
\text { recovery from work } \\
\text { Enhanced } \\
\text { opportunities to lead } \\
\text { work practices and } \\
\text { lifestyles that } \\
\text { promote work ability } \\
\text { and recovery from } \\
\text { work }\end{array}$ & $\begin{array}{l}\text { Establishing new } \\
\text { work practices and } \\
\text { lifestyles that } \\
\text { promote work } \\
\text { ability and recovery } \\
\text { from work (e.g., } \\
\text { reducing sedentary } \\
\text { behaviors, more } \\
\text { energy from } \\
\text { healthy food and } \\
\text { sufficient amount } \\
\text { of sleep during } \\
\text { night) }\end{array}$ & $\begin{array}{l}\text { Improved recovery } \\
\text { from work } \\
\text { Improved work } \\
\text { ability }\end{array}$ \\
\hline
\end{tabular}

\section{Planned work}

\section{Intended results}


Our team benefitted from having a clear goal of conducting evidence- and theory-based work, as this gave us a shared starting point against which to measure our choices. However, in this paper, we have explained that developing an intervention as evidence- and theory-based is not a straightforward task. The lack of and inconsistencies in evidence may raise challenges that require utilizing different types of evidence.

Although evidence is often ranked hierarchically in health sciences [16], we adopted a critical and realist approach [44-45] to the evidence by acknowledging the limitations of evidence hierarchies [53]. For example, when carrying out evidence-based planning, instead of relying on only the types of evidence that rank high in the hierarchy, one should consider scientific adequacy, relevance for current needs, and the ways in which the evidence addresses different values [54]. Thus, we utilized a variety of evidence (e.g., previous meta-analyses, experiences from previous interventions, and accumulated knowledge on health promotion professionals and interaction scholars) and reflected on the nature of this evidence and its limitations.

Furthermore, as suggested by the realist evaluation perspective, it is important to analyze not only what works but also how and why it works (or does not work), in which contexts and under which conditions [44-45]. In developing counseling content, the realist evaluation perspective was especially useful when a) making informed decisions when including BCTs with scarce or inconsistent scientific evidence, b) planning how effective BCTs should be operationalized in order to align with SDT (see Table 2), and c) applying evidence from different contexts to the context at hand (e.g. taking into account the possibility of limited social support for micro-entrepreneurs).

Integrating different types of theories and evidence related to behavior change enables planning counseling contents (BCTs and themes) for health promotion interventions in such a way that takes multiple perspectives into account. However, the process of integration is not straightforward when theories and evidence are based on potentially conflicting background assumptions. Further detailed reflections on the processes of developing theory- and evidence-based interventions are required within the field of health- and well-being-related counseling.

Researchers and health promotion professionals need to be transparent about their choices if they want to plan credible theory- and evidence-based counseling for health promotion interventions. Reflective descriptions of development processes and the challenges encountered during these may help other researchers and professionals avoid encountering the same challenges.

\section{References}

[1] K. Glanz, D.B. Bishop, The role of behavioral science theory in development and implementation of public health interventions. Annu Rev Public Health 31 (2010) 399-418. https://doi.org/10.1146/annurev.publhealth.012809.103604.

[2] L.K. Bartholomew, P.D. Mullen, Five roles for using theory and evidence in the design and testing of behavior change interventions. J Public Health Dent 71 (2011) 20-33. https://doi.org/10.1111/j.1752-7325.2011.00223.x.

[3] M. Gourlan, P. Bernard, C. Bortolon, A.J. Romain, O. Lareyre, M. Carayol, G. Ninot, J. Boiche. Efficacy of theory-based interventions to promote physical activity. A meta-analysis of randomized controlled trials. Health Psychol Rev 10 (2016) 50-66.

https://doi.org/10.1080/17437199.2014.981777.

[4] T.L. Webb, Y. Joseph, L. Yardley, S. Michie, Using the internet to promote health behavior change: a systematic review and meta-analysis of the impact of theoretical basis, use of behavior change techniques, and mode of delivery on efficacy. J Med Internet Res 12 (2010) 1, e4. https://doi.org/10.2196/jmir.1376. 
[5] A. Prestwich, F.F. Sniehotta, C. Whittington, S.U. Dombrowski, L. Rogers, S. Michie, Does Theory Influence the Effectiveness of Health Behavior Interventions? Meta-Analysis. Health Psychol 33 (2014) 465-74. https://doi.org/10.1037/a0032853.

[6] S. Michie, A. Prestwich, Are Interventions Theory-Based? Development of a Theory Coding Scheme. Health Psychol 29 (2010) 1-8. https://doi.org/10.1037/a0016939.

[7] S. Michie, M. Richardson, M. Johnston, C. Abraham, J. Francis, W. Hardeman, M.P. Eccles, J. Cane, C.E. Wood. The behavior change technique taxonomy (v1) of 93 hierarchically clustered techniques: Building an international consensus for the reporting of behavior change interventions. Ann Behav Med 46 (2013) 81-95. https://doi.org/10.1007/s12160-013-9486-6.

[8] S. Michie, R.N. Carey, M. Johnston, A.J. Rothman, M. de Bruin, M.P. Kelly, L.E. Connell. From theory-inspired to theory-based interventions: A protocol for developing and testing a methodology for linking behaviour change techniques to theoretical mechanisms of action. Ann Behav Med 52 (2018) 501-12. https://doi.org/10.1007/s12160-016-9816-6.

[9] G. Kok, H. Schaalma, R.A. Ruiter, P. van Empelen, J. Brug, Intervention mapping: A protocol for applying health psychology theory to prevention programmes. J Health Psychol 9 (2004) 85-98. https://doi.org/10.1177/1359105304038379.

[10] J. Ilmarinen, K. Tuomi, L. Eskelinen, C. H. Nygård, P. Huuhtanen, M. Klockars, Summary and recommendations of a project involving cross-sectional and follow-up studies on the aging worker in Finnish municipal occupations (1981-1985). Scand J Work Environ Health 17 (1991) 135-41.

[11] J. Verbeek, J. Ruotsalainen, J. Laitinen, E. Korkiakangas, S. Lusa, S. Mänttäri, T. Oksanen, Interventions to enhance recovery in healthy workers, a scoping review. Occup Med (Lond) 69 (2019) 54-63. https://doi.org/10.1093/occmed/kqy141.

[12] J. H. Laitinen, E. Korkiakangas, J.-P. Mäkiniemi, S. Tiitinen, P. Tikka, H. Oinas-Kukkonen, A.-M. Simunaniemi, S. Ahola, J. Jaako, M. Kekkonen, M. Muhos, K. Heikkilä-Tammi, H. Hannonen, S. Lusa, A. Punakallio, J. Oksa, S. Mänttäri, S. Ilomäki, A. Logren, J. Verbeek, J. Ruotsalainen, J. Ruusuvuori, T. Oksanen, The effects of counseling via a mobile application on microentrepreneurs' work ability and work recovery: a study protocol. Manuscript in revision for BMC Public Health.

[13] R.M. Ryan, E.L. Deci, Self-determination theory and the facilitation of intrinsic motivation, social development, and well-being. Am Psychol 55 (2000) 68-78.

http://dx.doi.org/10.1037/0003-066X.55.1.68.

[14] S. Michie, M.M. van Stralen, R. West, The behaviour change wheel: A new method for characterising and designing behaviour change interventions. Implementation Sci 6 (2011) 42. https://doi.org/10.1186/1748-5908-6-42.

[15] M. Kekkonen, H. Oinas-Kukkonen, P. Tikka, J. Jaako, A.-M. Simunaniemi, M. Muhos, Participatory Design of a Persuasive Mobile Application for Helping Entrepreneurs to Recover from Work, in: J. Ham, E. Karapanos, P. Morita, C. Burns (Eds.), Persuasive Technology, Springer, Cham, 2018. https://doi.org/10.1007/978-3-319-78978-1_14.

[16] D. Evans, Hierarchy of evidence: a framework for ranking evidence evaluating healthcare interventions. J Clin Nurs 12 (2003) 77-84. https://doi.org/10.1046/j.1365-2702.2003.00662.x.

[17] G.M. Manzoni, F. Pagnini, S. Corti, E. Molinari, G. Castelnuovo, Internet-based behavioral interventions for obesity: An updated systematic review. Clin Pract Epidemiol Ment Health 7 (2011) 19-28. https://doi.org/10.2174/1745017901107010019.

[18] D.B. Portnoy, L.A. Scott-Sheldon, B.T. Johnson, M.P. Carey, Computer-delivered interventions for health promotion and behavioral risk reduction: a meta-analysis of 75 randomized controlled trials, 1988-2007. Prev. Med 47 (2008) 3-16. https://doi.org/10.1016/j.ypmed.2008.02.014. 
[19] S. Schoeppe, S. Alley, W. Van Lippevelde, N.A. Bray, S.L. Williams, M.J. Duncan, C. Vandelanotte. Efficacy of interventions that use apps to improve diet, physical activity and sedentary behaviour: A systematic review. Int J Behav Nutr Phys Act 13 (2016) 127. https://doi.org/10.1186/s12966-016-0454-y.

[20] N. Hankonen, S. Sutton, A.T. Prevost, R.K. Simmons, S.J. Griffin, A.L. Kinmonth, W. Hardeman. Which behavior change techniques are associated with changes in physical activity, diet and body mass index in people with recently diagnosed diabetes? Ann Behav Med 49 (2015) 7-17. https://doi.org/10.1007/s12160-014-9624-9.

[21] D. McEwan, S.M. Harden, B.D. Zumbo, B. D. Sylvester, M. Kaulius, G.R. Ruissen, A.J. Dowd, M.R. Beauchamp. The effectiveness of multi-component goal setting interventions for changing physical activity behaviour: A systematic review and meta-analysis. Health Psychol Rev 10 (2016) 67-88. https://doi.org/10.1080/17437199.2015.1104258.

[22] S. Michie, C. Abraham, C. Whittington, J. McAteer, S. Gupta, Effective techniques in healthy eating and physical activity interventions: A meta-regression. Health Psychol 28 (2009) 690-701. https://doi.org/10.1037/a0016136.

[23] M.K. Shilts, M. Horowitz, M.S. Townsend, Goal Setting as a Strategy for Dietary and Physical Activity Behavior Change: A Review of the Literature. Am J Health Promot 19 (2004) 81-93. https://doi.org/10.4278/0890-1171-19.2.81.

[24] S.L. Williams, D.P. French, What are the most effective intervention techniques for changing physical activity self-efficacy and physical activity behavior - and are they the same? Health Educ Res 26 (2011) 308-22. https://doi.org/10.1093/her/cyr005.

[25] J. Bort-Roig, N.D. Gilson, A. Puig-Ribera, R.S. Contreras, S.G. Trost, Measuring and influencing physical activity with smartphone technology: A systematic review. Sports Medi 44 (2014) 67186. https://doi.org/10.1007/s40279-014-0142-5.

[26] M. Nour, J. Chen, M. Allman-Farinelli, Efficacy and external validity of electronic and mobile phone-based interventions promoting vegetable intake in young adults: Systematic review and meta-analysis. J Med Internet Res 18 (2016) e58. https://doi.org/10.2196/jmir.5082.

[27] E.L. Bird, G. Baker, N. Mutrie, D. Ogilvie, S. Sahlqvist, J. Powell, Behavior change techniques used to promote walking and cycling: A systematic review. Health Psychol 32 (2013) 829-38. https://doi.org/10.1037/a0032078.

[28] B. Gardner, L. Smith, F. Lorencatto, M. Hamer, S.J. Biddle, How to reduce sitting time? A review of behaviour change strategies used in sedentary behaviour reduction interventions among adults. Health Psychol Rev 10 (2016) 89-112.

https://doi.org/10.1080/17437199.2015.1082146.

[29] E.K. Olander, H. Fletcher, S. Williams, L. Atkinson, A. Turner, D.P. French, What are the most effective techniques in changing obese individuals' physical activity self-efficacy and behaviour: $A$ systematic review and meta-analysis. Int J Behav Nutr Phys Act 10 (2013) 29. https://doi.org/10.1186/1479-5868-10-29.

[30] C.J. Greaves, K.E. Sheppard, C. Abraham, W. Hardeman, M. Roden, P.H. Evans, P. Schwarz. Systematic review of reviews of intervention components associated with increased effectiveness in dietary and physical activity interventions. BMC Public Health 11 (2011) 119. https://doi.org/10.1186/1471-2458-11-119.

[31] M.S. McDermott, M. Oliver, D. Iverson, R. Sharma, Effective techniques for changing physical activity and healthy eating intentions and behaviour: A systematic review and meta-analysis. $\mathrm{Br} \mathrm{J}$ Health Psychol 21 (2016) 827-41. https://doi.org/10.1111/bjhp.12199. 
[32] J. Hartmann-Boyce, D.J. Johns, S.A. Jebb, P. Aveyard, and Behavioural Weight Management Review Group, Effect of behavioural techniques and delivery mode on effectiveness of weight management: Systematic review, meta-analysis and meta-regression. Obes Rev 15 (2014) 598609. https://doi.org/10.1111/obr.12165.

[33] S. Lusa, A. Punakallio, S. Mänttäri, E. Korkiakangas, J. Oksa, T. Oksanen, J. Laitinen. 2019. Interventions to promote work ability by increasing sedentary workers' physical activity at workplaces - A scoping review. Manuscript in revision.

[34] A-M. Simunaniemi, E. Korkiakangas, K. Vehmas, T. Oksanen, J. Laitinen. 2019. Effective dietrelated health promotion interventions in the workplaces. Systematic review. Submitted manuscript.

[35] E. Korkiakangas, J. Verbeek, J. Ruotsalainen, T. Oksanen, S. Klinkebiel, J. Laitinen. 2019. Workplace interventions for increasing physical activity or promoting healthy dietary habits or both, in small businesses. A scoping review. Submitted manuscript.

[36] S. Mänttäri, J. Oksa, S. Lusa, E. Korkiakangas, A. Punakallio, T. Oksanen, J. Laitinen. 2019. Interventions to promote work ability by increasing physical activity among workers with physically strenuous work: a scoping review. Manuscript in revision.

[37] A.B. Bakker, E. Demerouti, Job demands-resources theory: Taking stock and looking forward. J Occup Health Psychol 22 (2017) 273-85. https://doi.org/10.1037/ocp0000056.

[38] E. Järvelä-Reijonen, L. Karhunen, E. Sairanen, J. Muotka, S. Lindroos, J. Laitinen, S. Puttonen, K. Peuhkuri, M. Hallikainen, J. Pihlajamäki, R. Korpela, M. Ermes, R. Lappalainen, M. Kolehmainen. The effects of acceptance and commitment therapy on eating behavior and diet delivered through face-to-face contact and a mobile app: a randomized controlled trial. Int J Behav Nutr Phys Act 15 (2018) 22. https://doi.org/10.1186/s12966-018-0654-8.

[39] C.R. Patterson, J.B. Bennett, W.L. Wiitala, Healthy and unhealthy stress unwinding: Promoting health in small businesses. J Bus Psychol 20 (2005) 221-47.

https://doi.org/10.1007/s10869-005-8261-5.

[40] L.W. Green, M.W. Kreuter, S.G. Deeds, K.B. Partridge, Health Education Planning: A Diagnostic Approach, Mayfield Publishing, Palo Alto, CA, 1980.

[41] N. Nevanperä, A.-M. Keränen, O. Ukkola, J. Laitinen. Effects of Group Counseling Transmitted Through Videoconferencing on Changes in Eating Behaviors. J Nutr Educ Behav 47 (2015) 555-9. https://doi.org/10.1016/j.jneb.2015.07.004.

[42] L.N. Lyzwinski, A systematic review and meta-analysis of mobile devices and weight loss with an intervention content analysis. J Pers Med 4 (2014) 311-85.

https://doi.org/10.3390/jpm4030311.

[43] A.M. Müller, S. Alley, S. Schoeppe, C. Vandelanotte, The effectiveness of e-\& mHealth interventions to promote physical activity and healthy diets in developing countries: A systematic review. Int J Behav Nutr Phys Act 13 (2016) 109. https://doi.org/10.1186/s12966-016-0434-2.

[44] R. Pawson, The Realist Foundations of Evidence-Based Medicine: A Review Essay. Evaluation 24 (2018) 42-50. https://doi.org/10.1177\%2F1356389017746718.

[45] R. Pawson, T. Greenhalgh, G. Harvey, K. Walshe, Realist synthesis: an introduction. ESRC Research Methods Programme, University of Manchester, 2004.

[46] D.W. Maynard, J. Heritage, Conversation analysis, doctor-patient interaction and medical communication. Med Educ 39 (2005) 428-35. https://doi.org/10.1111/j.1365-2929.2005.02111.x. 
[47] E.L. Deci, R.M. Ryan, Self-Determination Theory, in: P.A.M. van Lange, A.W. Kruglanski, E.T. Higgins (Eds.), Handbook of theories of social psychology: Volume 1, SAGE Publications, Los Angeles, CA, 2012, pp. 416-37.

[48] M.N. Silva, M. M. Marques, P.J. Teixeira, Testing theory in practice: The example of selfdetermination theory-based interventions. EHP 16 (2014) 171-180.

[49] M.N. Silva, D. Markland, C.S. Minderico, P.N. Vieira, M.M. Castro, S.R. Coutinho, T.C. Santos, M.G. Matos, L.B. Sardinha, P.J. Teixeira, A randomized controlled trial to evaluate selfdetermination theory for exercise adherence and weight control: rationale and intervention description. BMC Public Health 8 (2008) 234. https://doi.org/10.1186/1471-2458-8-234.

[50] E.L. Deci, R.M. Ryan, The "What" and "Why" of Goal Pursuits: Human Needs and the SelfDetermination of Behavior. Psychol Inquiry 11 (2000) 227-68. https://doi.org/10.1207/S15327965PLI1104_01.

[51] K. Morton, M. Beauchamp, A. Prothero, L. Joyce, L. Saunders, S. Spencer-Bowdage, B. Dancy, C. Pedlar. The effectiveness of motivational interviewing for health behaviour change in primary care settings: A systematic review. Health Psychol Rev 9 (2015) 205-23. https://doi.org/10.1080/17437199.2014.882006.

[52] C. Neighbors, R. Knee, Self-determination and the consequences of social comparison. J Res Pers 37 (2003) 529-46. https://doi.org/10.1016/S0092-6566(03)00047-3.

[53] S. Nutley, A. Powell, H. Davies, What Counts as Good Evidence? Provocation Paper for the Alliance for Useful Evidence. Alliance for Useful Evidence, London, 2013.

http://www.alliance4usefulevidence.org/assets/What-Counts-as-Good-Evidence-WEB.pdf.

[54] D.W. Cash, W.C. Clark, F. Alcock, N.M. Dickson, N. Eckley, D.H. Guston, J. Jäger, R.P. Mitchell. Knowledge systems for sustainable development. Proc Natl Acad Sci USA 100 (2003) 8086-91. https://doi.org/10.1073/pnas.1231332100. 